\title{
Sustainability of Strategic Information Systems in Emergent vs. Prescriptive Strategic Management
}

\author{
Amin Hosseinian-Far, Victor Chang \\ School of Computing, Creative Technologies \& Engineering, Leeds \\ Beckett University, Leeds, UK
}

\begin{abstract}
Since the introduction of the 'Strategic Information Systems' (SIS) concept by Wiseman in 1985, there have been numerous efforts in incorporation of such systems by businesses for the very main reason of gaining competitive advantage. Considering the broad categorization of Strategic Management into emergent and prescriptive types, integration of SIS into business processes seems to be dissimilar in these two categories. This paper initially outlines the phases in the two types of strategic management approaches. It then intends to produce a framework for integration of SIS in each of the two methods. Lastly, the sustainability of SIS in emergent and prescriptive strategic management is compared. Our points of views on the Modern SIS have been presented.
\end{abstract}

Keywords: Strategic Information Systems (SIS), Prescriptive Strategic Management, Emergent Strategic Management, Systems' Sustainability

\section{Introduction}

According to Wiseman one of the first instances of the use of Strategic Information Systems (SIS) was by the American Airlines where it started operating reservation systems (1985). Although this might not be the paramount case, but is the one reported and published first in the contexts of strategic management and computing. Since then, emergence of new-fangled information technologies and the rapid pace of new technologies' appearances have had a great push towards incorporation of IT systems in organizations. Advances in knowledge management and representation, artificial intelligence, data warehousing and big data schemes are some instances of these developments. Today, many industries and businesses will be fragile without the use of information systems and technologies. Nonetheless, the techniques of integrating information systems at the strategic level of a corporation should correspond to the vision, mission and the purpose of that business (Issa-Salwe et al., 2010). Strategic approaches introduced by Mintzberg (1994) and Porter (1996) are in two different settings. The vision, mission and purpose, layout and attributes of these two management techniques are often unalike. The phases in each of these two strategic management categories are also dissimilar. Therefore assimilation 
of an SIS in business process which is following not the same approaches to strategic management will be likewise different. Once the SIS is embedded into the business processes, then there will be a question that for how long this SIS will give the business a competitive advantage. Gaining a Sustainable Competitive Advantage (SCA) through use of SIS would require a longitudinal study on a variety of case studies. However this might not be possible in emergent strategic management by which the company's strategy is set for a shorter period of time.

\section{Strategic Information Systems}

Strategic Information Systems are the information systems that assist the policy makers and strategic to align the business initiatives and bring opportunities to the business (McNurlin et al., 2005). The term was initially introduced by Wiseman (1985), however, further discussions and thoughts have been established ever since. Turban et al. introduce number of priorities for use of an IS for strategic alignment of a business:

1- Innovative applications

2- Competitive weapons

3- Changes in processes

4- Links with business partners

5- Cost reductions

6- Relationships with suppliers and customers

7- New products

8- Competitive intelligence (Turban, 2006)

Looking into Turban's factors, we would notice that each of the above mentioned priorities can be mapped in at least one of phases of both emergent and prescriptive strategic management framework. The priorities can also be mapped against other models and frameworks for SIS sustainability.

\section{Emergent Strategic Management}

In the emergent strategy, the objectives and some of the elements of the strategy are developed as the strategy goes ahead (Mintzberg, 1994). Usually such strategies are set for shorter periods of time compared to prescriptive strategic management approach. Such strategies are considered for volatile environments where full examination and establishment of the vision, mission and purpose cannot be accomplished (Mintzberg, 1994; Robinson, 2012). A good example of this can be Virgin Group which has adopted embryonic activities by entering different industries. In the UK alone the company now provides services and products through Virgin Atlantic, Virgin Cola, Virgin Mobile, Virgin Train, Virgin Money, etc. This approach intends to benefit the corporation by making money through a variety of operations and services. Although the company has 
suffered in certain industries due to challenges in the environment (Thompson, 1999), however has thrived in other sectors in the same period.

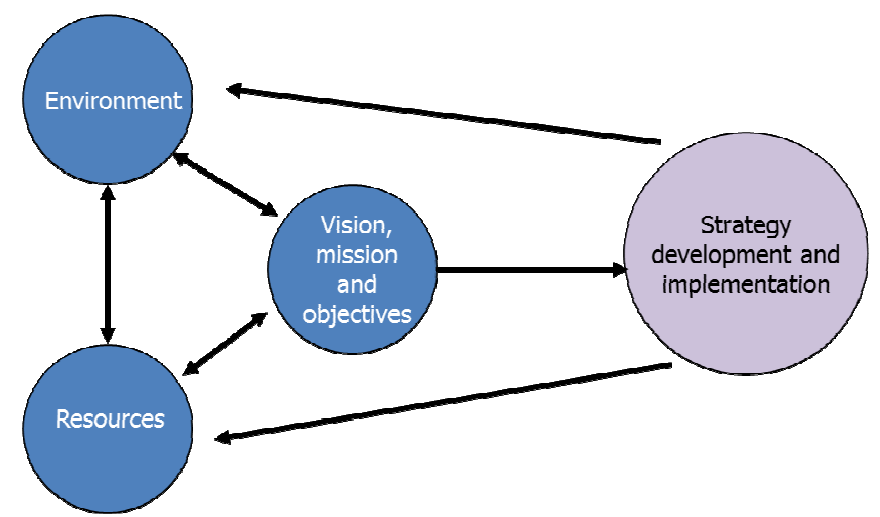

Fig. 1: Emergent Strategic Management (Lynch, 2003)

\section{Prescriptive Strategic Management}

The prescriptive strategic management is a more formalized method in which the objectives and elements of a strategy are set before the strategy is implemented (Porter, 1996). The analysis stage utilizes certain techniques for examining environments, analyzing resources and setting the mission, vision and objectives. There are certain Strategic Information Systems that can be implemented only in the analysis stage. The development phase considers the outcomes of the analysis stage and proposes number of options for the decision maker. The decision maker(s) would then selects an option or more than one option and rationalizes the selection(s). In the development phases also, an SIS can be applied. Such a strategic information system can be built upon the system dynamics and control in which quantitative and qualitative values from the analysis stage, can substitute certain variables and constraints in the SIS. The main advantage of using system dynamics modeling for business analysis and development of an SIS is that it can analyze and model business processes in a complex environment.

In the implementation stage, the decision makers should implement, supervise and control the strategy. SIS can again be supportive at this phase. 


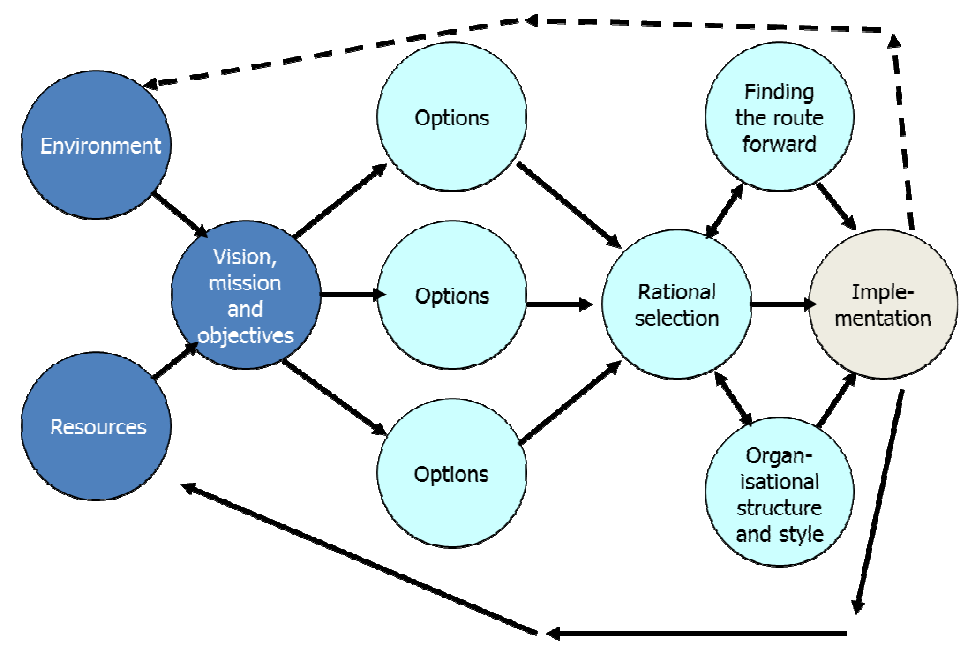

Fig. 2: Prescriptive Strategic Management (Lynch, 2003)

\section{SIS Integration}

Strategic Information Systems can be utilized at different phases of strategic management process. However, while the decision making process occurs in the development phase (using the information provided from the initial analysis stage), it would seem more valuable to have SIS integrated in the first two phases of strategic management processes. The integration not only depends on the business strategy, but also requires alignments from the IT infrastructure and organizational processes and structure (Issa-Salwe et al., 2010).

Table 1: SIS Integration by Phase and Type

\begin{tabular}{l|cc}
\hline \multicolumn{1}{c|}{ Phase } & Emergent & Prescriptive \\
\hline $\begin{array}{l}\text { Environment Analysis } \\
\text { (Analysis) }\end{array}$ & $\begin{array}{c}\text { Industry Analysis } \\
\text { Systems }\end{array}$ & $\begin{array}{c}\text { Industry Analysis } \\
\text { Systems }\end{array}$ \\
\hline $\begin{array}{l}\text { Resource Analysis } \\
\text { (Analysis) }\end{array}$ & $\begin{array}{c}\text { Financial and Resource } \\
\text { Management System }\end{array}$ & $\begin{array}{c}\text { Financial and Resource } \\
\text { Management System }\end{array}$ \\
\hline Objectives (Analysis) & Operational Systems & Operational Systems \\
\hline $\begin{array}{l}\text { Option Selection } \\
\text { (Development) }\end{array}$ & N/A & $\begin{array}{c}\text { Decision Support } \\
\text { Systems }\end{array}$ \\
\hline $\begin{array}{l}\text { Option Rationalization } \\
\text { (Development) }\end{array}$ & N/A & $\begin{array}{c}\text { Decision Support } \\
\text { Systems }\end{array}$ \\
\hline $\begin{array}{l}\text { Further Development } \\
\text { and Implementation } \\
\text { (Implementation) }\end{array}$ & Strategic Systems & Strategic Systems \\
\hline
\end{tabular}

Systems operating in each phase should read data from the same data warehouse. The super system can be considered as a single strategic information system for this business. 


\section{SIS's Sustainability}

Sustainability can be considered as a feature and attribute of a system (Hosseinian-Far et al., 2010). SIS's sustainability primarily rest on the sustainability of information systems (Griffiths and Hackney, 2006). There are number of studies which suggest that sustainability is another dimension of software attributes that should also be assessed. Nevertheless, the sustainability assessment of information systems is usually studied only from the economic point of view. There are seven systems' sustainability dimensions which should be considered before implementing the SIS (Jahankhani et al., 2009):

1- Technical: Technical domain which contemplates the throughput and output values, energy efficiency of the system (both physical and software),

2- Commercial: This category assesses the costs associated with the whole system's lifecycle from business requirements to the implementation. Moreover the break-even point for the costs. The outsourced or off the shelf price of the system would be evaluated if this is the case,

3- Environmental: The environmental domain overlaps with the some aspects of other classes and in which the impacts of the system on its environment will be assessed,

4- Reliability, Availability and Maintainability (RAM): This category seems to be an important domain for many businesses when incorporating new information systems. Similarly, the maintainability is very important in order to provide a endured operation of the system,

5- Safety and security: A system which is vulnerable to malicious attacks and does not offer secure operation does not deliver any value to a business,

6- Quality: Quality measures discusses the assurances given by a system's input and output and its errorless operations,

7- Perceived value

Jahankhani et al. (2009) argue that except the technical and commercial categories which are contexts specific, other categories can be assigned a measurable metrics. If we apply the above framework in context of strategic management and the use of strategic information systems, we can reach a context specific framework for SIS sustainability. Hence:

Table 2: Metrics for measuring SIS sustainability in emergent and prescriptive strategic management

\begin{tabular}{l|cc}
\hline \multirow{2}{*}{ Category } & \multicolumn{2}{|c}{ Metric } \\
\cline { 2 - 3 } Technical & Emergent & Prescriptive \\
\cline { 2 - 3 } & Normalized 0-1 range & Normalized 0-1 range \\
& quantitative metric: & quantitative metric: \\
& from Turban's priorities. & from Turban's priorities. \\
\hline Commercial & RoI, Breakeven (Short & RoI, Breakeven (Long \\
\hline
\end{tabular}




\begin{tabular}{l|cc}
\hline & Term) & Term) \\
\hline Environmental & $\begin{array}{c}\text { Normalized 0-1 range } \\
\text { quantitative metric }\end{array}$ & $\begin{array}{c}\text { Normalized 0-1 range } \\
\text { quantitative metric }\end{array}$ \\
\hline Safety and Security & $\begin{array}{c}\text { Mean Time Between } \\
\text { Failures (MTBF) }\end{array}$ & $\begin{array}{c}\text { Mean Time Between } \\
\text { Failures (MTBF) }\end{array}$ \\
\hline Quality & $\begin{array}{c}\text { Safety Integrity Level } \\
\text { (SIL) }\end{array}$ & $\begin{array}{c}\text { Safety Integrity Level } \\
\text { (SIL) }\end{array}$ \\
\hline Perceived value & $\begin{array}{c}\text { Normalized 0-1 range } \\
\text { quantitative metric, } \\
\text { Software Quality Plan } \\
\text { (SQP) }\end{array}$ & $\begin{array}{c}\text { Normalized 0-1 range } \\
\text { quantitative metric, } \\
\text { Software Quality Plan } \\
\text { (SQP) }\end{array}$ \\
\hline
\end{tabular}

Although the above mentioned categories and proposed metrics may seem to illustrate sustainable strategic information systems, however, does not guarantee a sustainable competitive advantage for the business. Porter's view on competitive advantage was based on two main rules of differentiation and cost leadership which were then aligned with the corporate strategy for gaining competitive advantage. The cost leadership is reflected in Jahankhani's et al. (2009) and Turban's (2006) research works; however differentiation is the missing category. The proposed category and metric framework for SIS sustainability is outlined below:

Table 3: Metrics for measuring SIS sustainability in emergent and prescriptive strategic management

\begin{tabular}{l|cc}
\hline \multicolumn{1}{c|}{ Category } & Emergent & Metric \\
\cline { 2 - 3 } Technical & $\begin{array}{c}\text { Normalized 0-1 range } \\
\text { quantitative metric: } \\
\text { from Turban's priorities. }\end{array}$ & $\begin{array}{c}\text { Normalized 0-1 range } \\
\text { quantitative metric: } \\
\text { from Turban's priorities. }\end{array}$ \\
\hline Commercial & $\begin{array}{c}\text { RoI, Breakeven (Short } \\
\text { Term) }\end{array}$ & $\begin{array}{c}\text { RoI, Breakeven (Long } \\
\text { Term) }\end{array}$ \\
\hline Environmental & $\begin{array}{c}\text { Normalized 0-1 range } \\
\text { quantitative metric }\end{array}$ & $\begin{array}{c}\text { Normalized 0-1 range } \\
\text { quantitative metric }\end{array}$ \\
\hline RAM & $\begin{array}{c}\text { Mean Time Between } \\
\text { Failures (MTBF) }\end{array}$ & $\begin{array}{c}\text { Mean Time Between } \\
\text { Failures (MTBF) }\end{array}$ \\
\hline Quality & $\begin{array}{c}\text { Safety Integrity Level } \\
\text { (SIL) }\end{array}$ & $\begin{array}{c}\text { Safety Integrity Level } \\
\text { (SIL) }\end{array}$ \\
\hline Perceived value & $\begin{array}{c}\text { Normalized 0-1 range } \\
\text { quantitative metric, } \\
\text { Software Quality Plan } \\
\text { (SQP) }\end{array}$ & $\begin{array}{c}\text { Normalized 0-1 range } \\
\text { quantitative metric, } \\
\text { Software Quality Plan } \\
\text { (SQP) }\end{array}$ \\
\hline Differentiation & $\begin{array}{c}\text { Normalized 0-1 range } \\
\text { quantitative metric }\end{array}$ & $\begin{array}{c}\text { Normalized 0-1 range } \\
\text { quantitative metric }\end{array}$ \\
\hline
\end{tabular}


For gaining a sustainable competitive advantage in a business, a differentiated SIS may also lead to a monopoly at the top level of business and therefore the whole business in the sector. Some of Turban's priorities such as innovation, competitive weapon and competitive intelligence would assist an SIS to be differentiated. To provide quantitative metrics for differentiation of an SIS, we can use statistical models to quantify heterogeneity.

\section{The Recent Development of SIS}

The recent development of SIS is an interesting topic due to the increasing demands and requirements on products and services. The focus has been directed to the improvement of services, customer satisfaction, business opportunities and profits. Galliers and Leidner (2014) describe a number of challenges and issues faced by organizations and businesses adopting SIS. They have recommended the use of their guidelines and best practices approaches. However, a number of these recommendations do not have the support from real case studies and services that can demonstrate the impacts and added values from organizations following SIS guidelines. Since the framework is a suitable method for demonstrating the effectiveness of delivering the recent development of SIS, it has been popular in modern services such as services offered by Cloud Computing. In particular, Cloud Computing Business Framework (CCBF) has been adopted by organizations seeking clear directions, recommendations, proofs-of-concepts and case studies of delivering Cloud Computing services (Chang, 2015). The use of Cloud Computing is a relevant illustration of SIS, since services have been requested by users and service providers meet their requirements (Galliers, Leidner, 2014; Chang, 2015). In the process of achieving service delivery via Cloud Computing, all the factors in Table 2 can be met. Cloud Computing is aimed to offer a good quality of service; deliver technical implementations; reduce the long-term costs; manage security and privacy centrally and respond to 'abnormal' activities promptly; improve on the environmental sustainability by scaling down the data center and provide added values for organizations that adopt Cloud Computing.

\section{Conclusion}

Jahankhani et al.'s framework for systems' sustainability has been applied to the context of strategic management. A brief comparison between the structure of an SIS and its sustainability in emergent and prescriptive strategic management is performed. A new dimension is added to the framework based on Porter's model for gaining competitive advantage, differentiation. Differentiation is not applicable in an evolving scenario such as emerging strategy due to its shorter duration period, nevertheless, can be ticked for SISs deployed in a business with 
prescriptive strategy. The use of Cloud Computing can illustrate the modern SIS efficiently and effectively to meet increasing demands and targets.

\section{References}

Chang, V. (2015) A Proposed Cloud Computing Business Framework, Nova Science Publisher.

Galliers, R. D., \& Leidner, D. E. (2010) Strategic information management: challenges and strategies in managing information systems. Routledge.

Griffiths, G. and Hackney, R (2001) Strategic Information Systems for Competitive Advantage: Planning, Sustainability and Implementation. s.1.: IDI Global.

Hosseinian-Far, A., Jahankhani, H. and Pimenidis, E. (2010) A review on sustainability models. 2010 Proceedings of Global Security, Safety, and Sustainability. Communications in Computer and Information Science Volume 92, pp 216-222

Issa-Salwe, A., Ahmed, M., Aloufi, K., \& Kabir, M., Strategic Information Systems Alignment: Alignment of IS/IT with Business Strategy. 1, s.1.: JIPS, 2010, Journal of Information Processing Systems, Vol. 6.

Jahankhani, H., Hsu, F. and Hessami, A. G. (2009) A Systems Framework for Sustainability. J London : Proceedings of International Conference on Global Security, Safety and Sustainability.

Lynch, R (2003). Corporate Strategy. London : Prentice-Hall.

McNurlin, B. C. and Sprague, R. H. (2005) Information Systems Management in Practice. 7. New Jersey : Prentice-Hall.

Mintzberg, H. (1994) The rise and fall of strategic planning: Reconceiving roles for planning, plans, planners. Toronto : Free Press.

Porter, M (1996). What is a strategy? s.l. : Harvard Business Review.

Robinson, R (2012). Insights on Integrating Special Projects with Organizational Strategy. s.1. : ABARIS.

Thompson, J. L. (1999) A strategic perspective of entrepreneurship. 6, International Journal of Entrepreneurial Behaviour \& Research, Vol. 5, pp. 279-296.

Turban, E., et al (2006). Electronic Commerce 2006: A Managerial Perspective. New Jersey : Prentice Hall.

Wiseman, C (1985). Strategy and Computers: Information Systems as Competitive Weapons. s.l. : Dow Jones - Irwin. 